\title{
Aesthetics as metaphysical meaning-making in the face of death
}

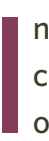
$n$ my ethnographic research on death and dying in contemporary Finland, I explore how Finns facing end of life due to a long-term illness or other terminal condition seek to orient themselves and make meaning with cultural tools such as imagery, language, and metaphysical thinking. My primary research material is based on extensive fieldwork at Terhokoti Hospice and in the cancer clinic of Helsinki University Hospital, where I have had numerous conversations with terminally ill patients. This paper seeks to explore the way in which metaphysical aesthetics is assuming the role that religious thinking has traditionally played. When the role of institutional religion is diminishing, it becomes important to understand how emotional and spiritual resolution can be arrived at by means of aesthetics.

\section{Prologue: a blackbird}

Heidi was a woman in her fifties suffering from colon cancer. Even though seriously ill, she had been physically active until recently. A definite turn for the worse had happened suddenly, and now she was admitted to the Terhokoti hospice ward. The cancer was pretty much everywhere in her body, destroying her spine. She was bedbound and fragile, yet her mind was still perky. Because of the metastasis in her brain, her memory sometimes lapsed and her speaking was becoming more difficult. Words occasionally escaped her, yet she was eager to talk with me.

During our conversation, Heidi spoke about her sickness and reflected on her relationship with God, which had become more distant. Now I was accompanying Heidi to breakfast and I was just about to leave when she suddenly called me back. 'There is something I still want to share with you, just in case, we don't... you know. She had a meaningful look on her face, and I understood the implication of her words: just in case we don't meet again. She started to tell me a story and I hastily set up my recording device:
I had my grandson at my home and I was put- ting him down for a nap when I heard a sound from the front yard. A cracking noise and so on. The dog was alerted also, so we went downstairs to see... A hawk was eating a blackbird, there in my front yard. [She used her phone to show me a picture she had taken, but the picture was not very clear.] The front yard was full of black feathers, all over the yard, on the white snow. They were there for months, those black feathers, in the yard, and pieces of bones and the head and everything. It was somehow very relieving to me at that point... I was imagining and picturing that I myself am the blackbird being eaten by the hawk there... that I am going... to the cycle of the nature. It felt very good... gentle, as a thought...

After finishing the story, Heidi remained quiet for a while. Then she emphasized the meaningfulness of the event by stressing how impressive the experience was. She wanted to explain the significance of nature to her in general; her relationship with nature had grown closer over the past few years. In particular, her connection with birds had become stronger since she had started learning about forest birds.

I knew instantly that I was sharing an important memory. But while this story was interesting in a number of ways to me as a researcher, why was it so important to Heidi that she felt that she needed to tell it as - literally - her last words to me? The 


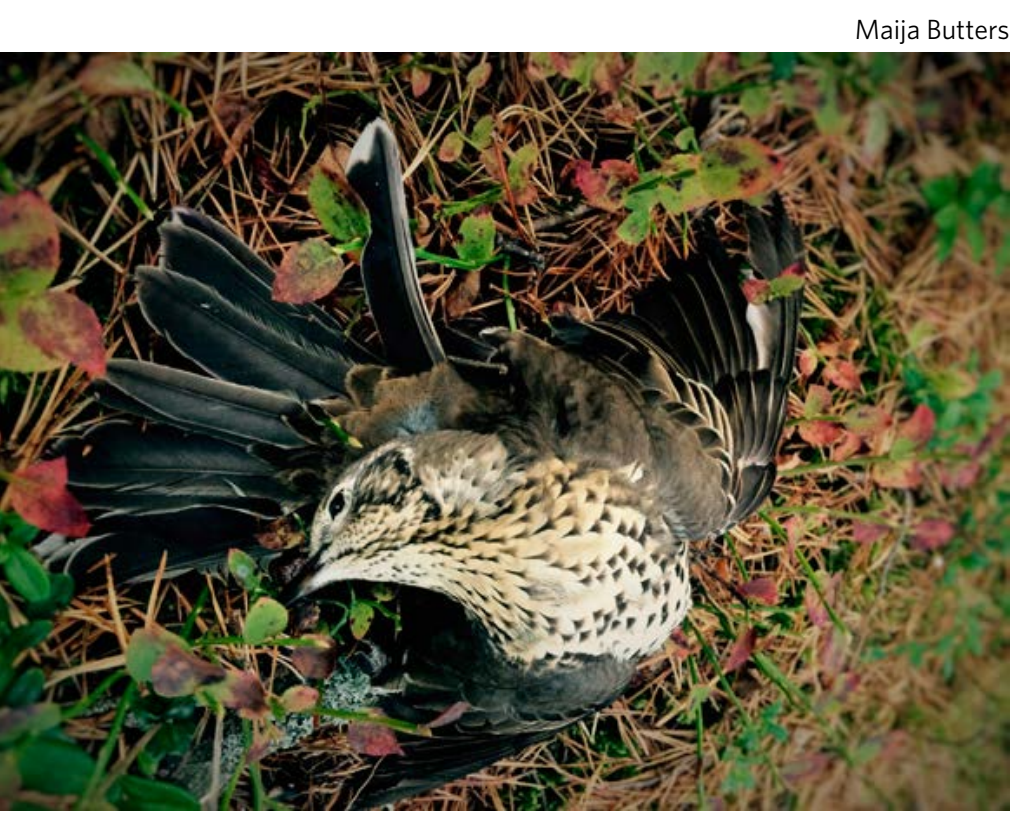

Dead bird in the autumn forest.

story seemed to represent a sort of turning point or revelation. Looking at the dying blackbird, she knew she would be dying from the cancer. But how did she know that? One could claim that it was simply an obvious analogue between her and the bird, with the hawk representing her cancer, which was attacking her body, the blackbird. She probably did have a strong embodied experience, in which the analogous elements between her and the bird impressed her. But this does not fully answer the question of how she gained insight into her own existential situation.

The work of the British philosopher Ronald Hepburn helps to illuminate Heidi's story. Hepburn (2004: 127) writes that aesthetic scenes may sometimes be experienced 'as revealing something fundamental (and no doubt grim) about how things really, or ultimately, are'. Furthermore, aesthetic experiences occasionally do not cause a realization about ultimate reality per se, but instead seem to point to something completely other, to 'a transcendent Source for which we lack words and clear concepts', as Hepburn (ibid.) suggests. In Heidi's case, her experience was very poignant in terms of 'how things ultimately are'.

Reflecting on Hepburn's words, I realized that I had heard other stories from my research participants where an aesthetic experience had led them to a realization of their existential situation and the ultimate reality of things. This sort of aesthetic appreciation is involved in what Hepburn (2004: 127) calls 'metaphysical imagination'. For reasons that I will explore and explain in this paper, however, I would call it 'metaphysical meaning-making'. Metaphysics can be defined as an inquiry into the ultimate nature of things, a study about what ultimately is and what it is like. Therefore, the limits of being and questions about non-being are essentially metaphysical matters. Often actualized by terminal illness, these were reflected on in various ways by my study participants.

In this article, I will describe and analyse experiences which proved to be illuminating to my study participants in regards to their metaphysical meaning-making around death and dying. It became clear to me during my research that aesthetics, as a way of thinking about and processing matters of life and death, is vaster and more varied than the examples in this article may suggest. Thus, I will focus on the philosophical premises of the phenomenon that I call 'aesthetics as metaphysical meaning making. The article begins with a short introduction of my research material and a description of the ethnographic process. Then I will define my theoretical frame of 'cultural embodiment', developed by Thomas Csordas, and some of the key concepts of the study. This will be followed by actual analysis of the experiences. I conclude by offering a general overview of the meaning of aesthetics for dying people, as well as by discussing the concept of 'metaphysical meaningmaking' and 'aesthetic experience' as useful conceptual tools at the end of life.

\section{Ethnographic research data}

This article is based on ethnographic research data ${ }^{1}$ which I gathered during the years 2014-16. The study of death and dying, especially in ethnographic settings, includes ethical issues which have been carefully considered while planning the course of the study. The Ethical Board of the Hospital District of Helsinki and Uusimaa (HUS) granted approval for the study, which included signed consents from over twenty participants.

1 The research data, collected from Terhokoti Hospice and the Cancer Clinic of Helsinki University Hospital (HYKS), comprises recorded and unrecorded interviews and conversations, in addition to research diaries. According to the Hospital District of Helsinki and Uusimaa (HUS) guidelines, the data will be archived for ten years upon completion of the study, after which it will be destroyed. Although this practice is unusual in the social sciences, it is typical in the medical field, especially in the case of a sensitive area of research, such as hospice and palliative care. 
In the beginning of 2014, I started visiting the so-called 'day group' at Terhokoti Hospice. The day group consists of patients accepted as patients at the hospice, but who are still capable of living at home and receiving palliative care at other medical institutions, such as the cancer ward at HYKS. Being the first step in hospice, the transition is often very emotional and significant for the patients, even though one can remain in the day group for years before actual admission to the ward at Terhokoti.

I paid weekly visits to my 'Tuesday crew' during the spring of 2014. In the summer, when the day group stopped meeting, I conducted research for a few weeks in the hospice ward itself, where I spent 6-12 hours per day. I continued to be in contact with my Tuesday crew by phone, as well as by sometimes visiting them in their homes. For a few weeks, I also visited the cancer ward at HYKS on a daily basis, when I simply followed the daily routine and spoke here and there with patients, family members, and hospital staff. Occasionally I also found patients who were interested in the research. I continued to visit Terhokoti until the spring of 2016.

In this way, I met a number of different kinds of informants. I spent only a few hours talking with some, sometimes recording our conversations. Others I met with over a longer period of time. Finally, there were also patients who became so-called 'key informants' in a classic anthropological sense. Given the longer time span, close relationships developed, some of which are still active.

The examples I present in this article are chosen from this material, on both the basis of their relevance and their variety. Although aesthetics is related in multiple ways to the lives and deaths of my research participants, here I seek to discuss the moments that especially illuminate the spontaneity of aesthetic experiences and the multiple ways in which they manifested in the everyday life of the patients. Each story is different - and yet they share a common aspect of aesthetics.

In this article, I will be talking about Heidi and Oiva, who were patients at Terhokoti, and Martti and Helena, whom I met at the hospital. ${ }^{2}$ All of these patients were close to me, especially Martti and Helena, whom I knew for a long period of time.

2 The names and some personal details have been changed in order to protect the identities of the research participants.
During the summer and autumn of 2014, I also experienced a personal loss: my mother was diagnosed with inoperable cancer in June and she died in October, only four months later. Sharing with her about her medical treatments, as well as witnessing her personal struggle with the illness, naturally broadened my perspective.

\section{Terminal illness:}

\section{methodological thoughts from the field}

From my perspective as a researcher, and also as a daughter whose mother passed through a brief but intense period of illness before death, I see terminally ill people often facing a chaotic life situation filled with daunting questions and tensions, ranging from various social issues to physical, psychological, and existential uncertainties. In our contemporary society, where people's social roles are created mainly on the basis of professional and economic status, as well as their bodily health and youthful outlook, the change that terminal illness brings about is drastic. Change contains many aspects, from the purely pragmatic challenges of everyday life to more philosophical questions about the value of human life. In practice, the ordinary everyday reality of a working person changes quite suddenly to that of a sick pensioner, whose free schedule is structured perhaps only by (ir)regular meetings at various medical clinics, and for whom the only certainty is death. On the other hand, when bodily functions start to fail, questions of dignity and the value of human life arise in many patient's minds, causing anxiety.

Talking about death and dying in the first or second person continues to be a more or less taboo subject, even - or perhaps especially - among terminally ill patients. Thus, whenever my research patients started sharing their thoughts or feelings about death and dying, it was always a rare and special moment. I seldom asked about these things directly; instead I waited for patients to open that conversation, as I wanted to see how they would initiate the topic. By listening attentively, I was able to recognize their tentative attempts to apprehend their situation. This article deals with those exact moments when my research patients started to open up and share experiences which had pushed them to think of their own death and enabled them to realize something crucial about their existential situation.

During the first six months of my ethnography, I 
did not initiate the theme of 'art' or 'aesthetics' in conservations with my research patients unless it was present in their lives in some obvious way, as was the case with a pair of artists. After sensing that there was something noteworthy about the theme, however, I did begin inquiring about it. I would ask about the patient's relationship with art or about their aesthetic experiences in general. I only used the term 'aesthetic' (esteettinen in Finnish) quite rarely, as in everyday usage the term has a somewhat multivalent meaning: many people think that aesthetics refers automatically to beauty, whereas in a scholarly sense the concept can mean anything that people find meaningful in a sensorial way (see e.g. Plate 2005). With some participants, however, the conversation shifted to quite explicitly include the meaning of aesthetics and art for them.

In an analytical sense, the concept of 'aesthetic experience' emerged only after doing ethnography for over a year. I had paid attention to stories - like Heidi's above - which were seemingly meaningful to the study participants, but it was only later that I realized their common features and labelled them 'aesthetic experiences'. Thus, the notion of aesthetic experience was originally an etic term introduced by me. As we will see, one of the research patients discussed here resonated with the term so much that she started using it quite deliberately, as if it was analytically useful for her as well, in an emic manner.

After focusing on the theme, I realized that issues of art and aesthetics are present in many of my research patients' lives, either in special moments or in everyday situations. Some of them actively engaged in the creation of art, such as writing, painting, picture-making, and so on. One of the research participants had even taken part in another study concerning the meaning of visual art at the end of life, for which she had written about her experiences with certain paintings. Some had consciously looked for an aesthetically pleasing environment where they
Maija Butters

could meditate or rest when feeling especially sick. It is a well-known fact that art has a beneficial effect on health (see Nummelin 2011).

Manifold uses of art and aesthetics can be meaningful for patients when they are in the process of making sense of their situation. Here I focus on aesthetic experiences, which at times were actively sought after (for instance, by reading poetry), but which often also happened quite suddenly and accidentally, making deep impressions (as seen in Heidiss story). My main argument is that these sorts of aesthetic experiences help people to handle complex and ambiguous existential issues and that they facilitate metaphysical meaning-making in a challenging existential situation. The purpose of this article is to analyse what happens in these experiences and how metaphysical meaning-making is possible. I use the general theoretical approach of cultural phenomenology as developed by the anthropologist Thomas Csordas (1990, 1994, 1999). In my analysis, I also use notions from various phenomenological and existentialist philosophers on aesthetics.

\section{Cultural phenomenology and an aesthetic experience}

The phenomenological way of seeing the human position in the world seems to be effective when studying temporal and situational subjects, such as a dying person. The Husserlian critique towards the scientific manner of relating to the world as the only legitimate way of achieving adequate information about it is poignant when one is trying to gain an understanding of such ideas as 'being' and 'non-being. In other words, when one is forced to face the paradox of 'death within life,' 'ending time', or 'non-existence', scientific (medical) language offers few tools to comprehend the situation and grasp the finality of existence. Furthermore, according to my experiences in the field, religious language only speaks to some people. It may be able to console them, but for the most part, 
Finns, especially in the Helsinki area, tend towards a more secular view or have a relationship with spirituality which is not aligned with traditional Lutheran theology or language. Therefore, there seems to be a certain void regarding an adequate language of death. ${ }^{3}$ Ultimately, it may even be, as Husserl seems to claim with the concept of 'inner time', that man cannot grasp the idea of a last moment, timeless time, and the finitude of personal existence (Heinämaa 2010: 88).

The lack of a 'language of death' causes further questions about the relation of language to experience. Commenting on the prior emphasis on textuality, discourse, and representation in the fields of anthropology and religious studies, Csordas (1999) points out that there has been somewhat of a tendency to reduce human experience to language. Noting how my research participants tried to communicate their thoughts and feelings about the end of life, dying, and death, it is easy to see how they found it hard to express themselves verbally (or in any way even), as if accurate and adequate words were missing. ${ }^{4}$ However, this lack of language does not refer to a lack of an experience of dying. I would claim rather that because the experience of terminal illness is so powerful, there is an acute search for meaningful methods and means to handle, think, and communicate about it. Experiences of aesthetics derive their meaningfulness from this need to communicate.

The experiences discussed in this article were, of course, communicated to me via language, and usually they were told in the form of a story or a narrative, which seemed to be already formed in the mind of the patient. The subject of my analysis is not the linguistic format or the rhetoric of those stories. Although this could be one way to approach the sub-

3 In February 2016, I attended a symposium on death (Kuolema Symposium) in Joensuu where various professionals in the field of death and dying (such as priests, doctors and nurses) were lecturing. In one of the conversations, someone stated that in Helsinki, the traditional Christian spiritual language 'doesn't speak to people any longer', and that there is a 'need to develop new kinds of religious expressions in order to touch people'. In an article in Helsingin Sanomat (5.4.2015), the hospice patient Pietari Vanhala states: 'We don't even have a vocabulary to handle the death of those who do not believe in a soul or the supernatural.'

4 About the limits of words in regard to dying, see also Irving 2009. ject matter, following Csordas I do not look at these stories as linguistic representations but instead treat them as embodied experiences.

In the theoretical approach of cultural phenomenology, an experience is not seen as constituted by language; rather, language discloses an experience. Csordas does not deny the denominative and creative power of language, but he suggests a way to study experiences that emphasizes their embodied nature over their representational aspects. Semiotics has its place in cultural studies, but in cultural phenomenology the focus lies more in the participatory and relational aspect of human experience: 'semiotics gives us textuality in order to understand representation, phenomenology gives us embodiment in order to understand being-in-the-world' (Csordas 1999: 146-7).

Here the term 'embodiment' can be seen empirically as a basic human relationality towards the world, stressing our bodily engagement with it. Embodiment is also understood as 'the existential ground of culture and self' (Csordas 1994: 6), which suggests that we are able to find our way to culture or ourselves only via our bodily existence. Therefore, studies that focus on embodiment are ultimately not about the body per se, but about 'culture and experience ... understood from the standpoint of bodily beingin-the-world' (Csordas 1999: 143). This paradigm of embodiment provides us with a way of finding 'a sense of existential meaning beyond representational meaning' (Csordas 1999: 147), which is exactly what I am interested in doing in my study.

Thus, instead of analysing isolated representational elements or themes of stories, as interesting as they may be (such as Heidi's reference to the cycle of nature), my task in this article is to focus on experience as a unit in itself while treating the concept of an experience in a Deweyan sense, following his theory of aesthetics (Dewey 1980 [1934]). Simply put, John Dewey differentiated experience from an experience. We are constantly having experiences, and life is constituted by a chain of experiences which in essence is 'the result of interaction between a live creature and some aspect of the world in which he lives' (Dewey 1980: 4). This quote shows that Dewey's understanding of the human position in the world involves relationality and is akin to Heidegger's 'being-inthe-world'. The kind of experiences I focus on here can be seen as an experience, which has a unity of its own: '... we have an experience when the material experienced runs its course to fulfilment.' Dewey 


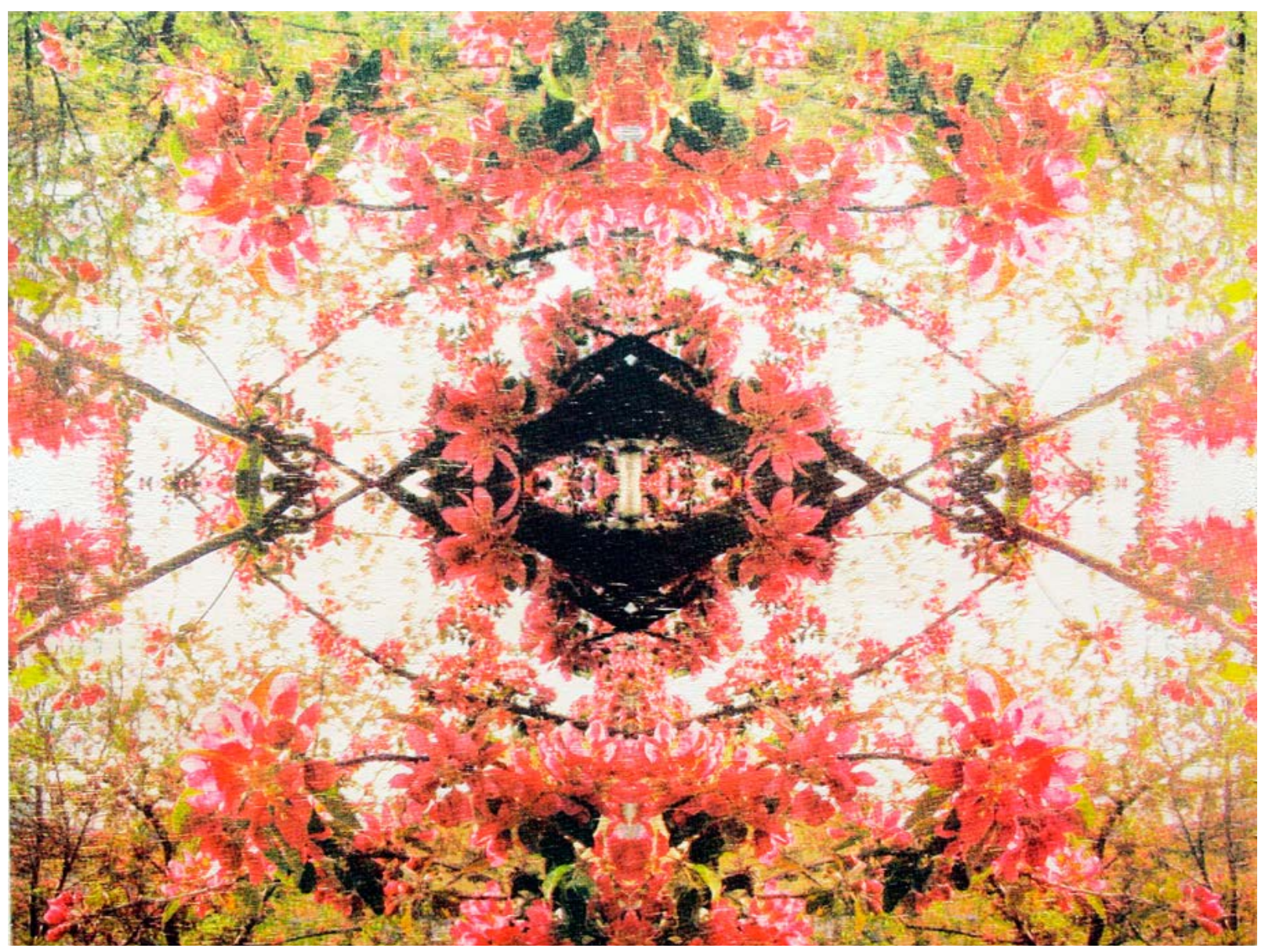

Unity (pink) by Sirkku Ketola, silkscreen on plywood, 39cm×51cm.

explains, 'The existence of this unity is constituted by a single quality that pervades the entire experience in spite of the variation of its constituent parts' (35-7). Dewey assumes that every real experience also has certain aesthetic qualities, such as structure and rhythm; therefore, an experience is always aesthetic experience. ${ }^{5}$ In regards to actual art products, Dewey posits that aesthetics is not merely found in artistic objects or in the audience, but that aesthetics happens in the experience, in the relational act of experiencing - hence the title of his book Art as Experience (1934).

The term 'art' is also treated here in a Deweyan sense: 'Art is a quality of doing and of what is done' (Dewey 1980: 214). In other words, instead of seeing art as a thing, art is understood as a quality. Here I refer to art in exactly this way: art is a quality that can

5 As pointed out by Kalle Puolakka (2014), Dewey never explicitly defined the concept of an 'aesthetic experience', yet this kind of interpretation arises quite naturally from his writings. be found in various places and acts. This also seems to be the way that most of my research participants used the word 'art' - although some research participants never explicitly talked about 'art' per se, but simply made references to certain novels or poems, for instance, which had caused them to engage in metaphysical thought.

\section{Embodied perception and disrupted intentionality}

Aesthetic experiences can be seen as highly embodied experiences. It is my hypothesis that it is precisely this embodied aspect that makes aesthetic experiences so powerful - and also insightful - for the patients. ${ }^{6}$ This aspect is apparent in many of the stories, but here I will share Martti's story, which is illuminating in terms of how his whole bodily being was affected by his aesthetic experience. Martti is an important

6 About embodied aesthetics and metaphysical experience, see e.g. Thorgeirsdottir 2010. 
example, as he had a strong Christian faith, unlike most of my research patients.

Martti (6o years old) had been seeing a doctor for a while because of severe tiredness and a lack of energy. When a swelling suddenly appeared in his testicles, cancer was immediately suspected (and tests later confirmed lymphoma). Martti was sent to the hospital for an ultrasound. Sitting in his car with the radio on, he heard a certain piece of classical music: John Tavener's Eternal Memory. ${ }^{7}$ Martti felt that the music 'went to his soul', and he had a vision. He saw himself in a beautiful green landscape, literally in 'green pastures', which he interpreted without any hesitation to be paradise. He felt very safe: 'I suddenly felt very good, that this [afterlife] isn't such a bad alternative to this [world]. I have seen this [world] already for 60 years... [The vision] was a perplexing experience.' This sensory experience made a strong impact on Martti, and he referred to it during our very first interview in July 2014, and then again in the autumn of 2015. Martti explained to me why the experience was so powerful: he thereby knew that it was all ok; there was nothing to worry about. I was either going to be cured, or, if not, I was going to be with God. There were only two alternatives - and they were both good ones.'

Martti was a believer, but it wasn't the word of God or a prayer that opened his heart to this deeply calming realization about his situation. It was music, an auditory and aesthetic experience, which led to another aesthetic experience, in the form of a vision of paradise, which he later connected with the famous passage in the Psalms: 'He makes me lie down in green pastures. He leads me beside still waters; he restores my soul' (Psalm 23:2-3). Also significant was the fact that Martti referred to this incident when I asked him about his overall feelings or thoughts about his situation. This had been the moment when an attitude, or a perspective, about his existential situation was born in him. Given his level of faith, it was not surprising that he felt confident. The striking point was that a visual experience and the impact of music - the aesthetics of the situation - brought him this confidence.

Martti's story raises the question of percep-

7 At the time he did not know this particular piece of music, but after being impressed by the experience he later went online to do a search about the radio program in order to find the name of the composer and the piece in question. Since then, he often listened to it.

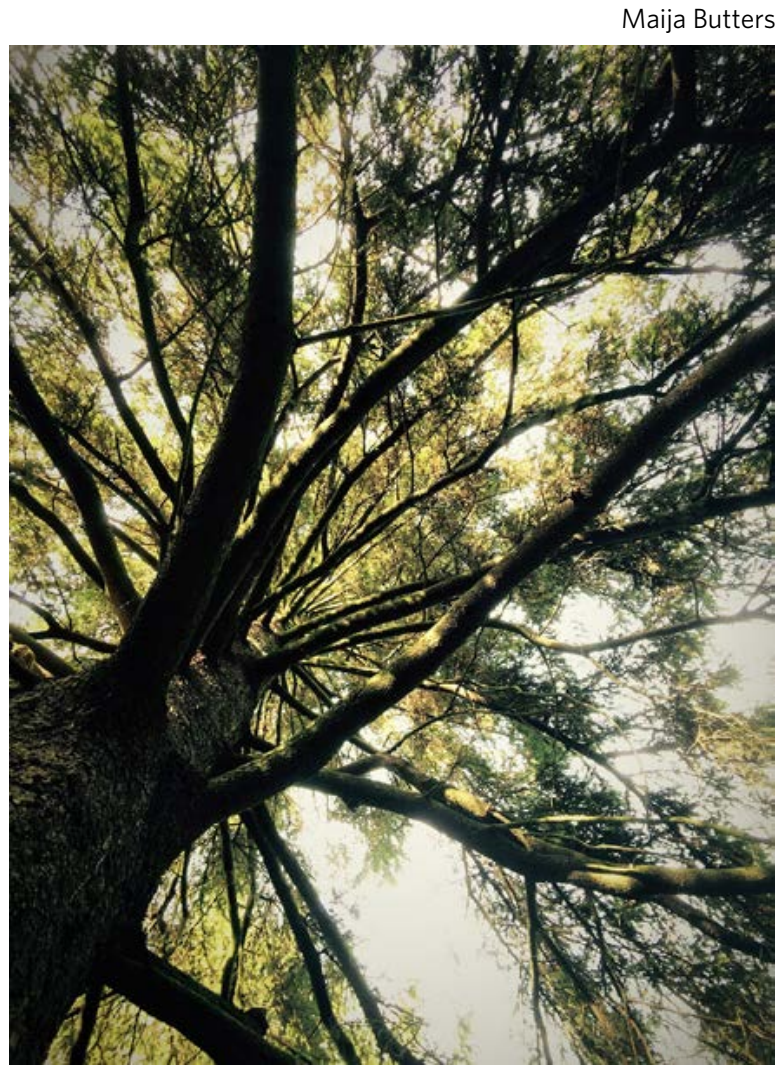

Spruce.

tion. The phenomenological approach to perception emphasizes the bodily dimension of perceptual experience, that is, what is perceived in us. Perception happens in the body with the faculties of the body - a notion that was especially important to Maurice Merleau-Ponty (2005 [1945]). Martti heard the music with his ears, felt safe in and with his body (as well as with God), and saw himself with his body in green pastures. Criticizing the Cartesian dualism of mind and body which does not respond to our experience of the world, of being-in-the-world, Merleau-Ponty holds that meanings happen in an intertwined connection of subject and object. When one's body is sick, one is in - or with - that body, and experiences and questions about the relationality of mind and body arise in multiple ways. Martti's story demonstrates how meaning-making happens in an intertwined aesthetic connection between the inner (subjective) reality and the outer (objective) reality.

Intentionality is another key concept that explains human positioning in the world, and it is of special interest in my study of the experiences of the dying. We are always intending the world in some specific way; as humans, we are always positioned towards something with an intention to make sense of it. 
Learning about terminal illness causes a disruption in the previous positioning and shifts our intentionality, bringing death into our immediate horizon. By this disruption, we are pushed towards a more conscious manner of looking at the world and our place in it - a philosophical exercise that existentialists would call 'an active practice of the human freedom', whereas for phenomenologists it would denote the practice of 'disclosing the world' in which intentionality, referring to a manner of relating to the world, largely dictates experience (Deranty 2015).

It might be useful here to follow Husserl's distinction, noted by Merleau-Ponty (2005: xx), of the intentionality of an act and operative intentionality. Intentionality of an act refers to our everyday judgements, meaning the conscious and voluntary positions and attitudes that we take towards the world and its phenomena. Operative intentionality, however, is something more embodied, non-representational and pre-conceptual. In Phenomenology of Perception (2005: 498), Merleau-Ponty writes: 'We found beneath the intentionality of acts, or thetic intentionality, another kind which is the condition of the former's possibility: namely an operative intentionality already at work before any positing or any judgement...' Following Merleau-Ponty, operative intentionality can be understood as arising from our deep bodily engagement with the world: 'The world is inseparable from the subject, but from a subject which is nothing but a project of the world, and the subject is inseparable from the world, but from a world which the subject itself projects' (2005: 499$500)$. We are always already in the world, and our 'consciousness is already at work in the world' (2005: 502), and hence we always have some engagement with it before any conscious propositional thought.

Mark Johnson (1987, 2007; see also Lakoff and Johnson 1999) has continued to develop MerleauPonty's idea of operational intentionality, for instance by linking it with the recent findings of cognitive science. In The Meaning of the Body, Johnson (2007: 51) writes about body-based meaning-making, which he calls embodied or immanent meaning. ${ }^{8}$ For Johnson,

8 Johnson and Csordas are not alone in emphasizing the embodied aspect of meaning-making. Since the 1990s, the humanities and social sciences have witnessed what some scholars call a 'sensory turn' (Howes 2015: vii) with renewed interest in the bodily, sensory, and aesthetic aspects of being, as well as intentionality arises primarily from our bodily existence: 'we learn to understand our world not with conceptual and propositional knowledge, but more fundamentally, via bodily interactions and feelings' (ibid.). Intersubjectivity also plays a crucial role in the process: we are not isolates but we learn and live in relation to others, 'in and through others' (ibid.).

It is quite natural that both kinds of intentionalities - intentionality of an act and operational intentionality - are shifted during a time of terminal illness. When the body starts to fail, it disrupts our corporeal engagement with the world. I witnessed my study participants attempting to redirect their intentionality in such a way that it would bring about a meaningful relationship with their life, end of life, and ultimately death. For some, aesthetic experiences helped them in this process. However, this was not always possible, and it was not possible for everyone.

During the months of my ethnography, I spent hours by the bedside of a number of dying people. Not all of them were research participants, but as I also served as a volunteer during my ethnography in Terhokoti Hospice, I was sometimes sent to simply stay by the patients' bed. During this time, as well as during the period I spent with my mother when

emphases on the study of experience inspired by philosophers such as Merleau-Ponty and Dewey. For instance, Michael Jackson's (1996, 2013) work on phenomenological and existential anthropology is important here, as is the interdisciplinary field of 'somaesthetics' introduced by Richard Shusterman $(1999,2012)$ and discussed further in Journal of Somaesthetics (founded in 2015). In the field of anthropology, studies in 'anthropology of the sensible, or 'sensory anthropology', have gained increasing interest (see e.g. Howes 1991; Howes and Classen 2014; Ingold 2000, 2011; Laplantine 2015 [2005]; Pink 2009; the journal The Senses and Society, launched in 2006). In the field of religious studies, Diana Eck shifted the focus to the materiality and visuality of religion already in 1981 with her book on darshan, which has since been followed by such scholars as Birgit Meyer (2015), Jon P. Mitchell and Michael Bull (2015), David Morgan $(2005,2010)$ and Brent S. Plate (2005), leading to the creation of a new journal, Material Religion, in 2005 . Interestingly related to the subject matter of this article, recent publications by the anthropologists Robert Desjarlais (2016) and Andrew Irving (2016, see also 2013) are about death and dying in Nepal and New York, respectively, discussed from an embodied, perceptual, aesthetic, and phenomenological point of view. 
she was sick, I witnessed a kind of internal uneasiness, which I would describe as a deep metaphysical disorientation - or as a disrupted operative intentionality. At times, the patient did not know whether they should strive for life or death, try to concentrate on breathing, or wish for the breathing to stop forever. Sometimes this intensified in outbursts of cries of despair. These were intense moments expressed via bodily motions, usually without any words.

To summarize, intentionality is a helpful concept when looking at a person's positioning in the world. Operational, or functional, intentionality can be seen as an elementary feature of human life, as it facilitates developing a meaningful relationship with the world. Being diagnosed with a terminal illness challenges our previous ways of perceiving and relating to life, thereby also disrupting our intentionality. Here aesthetic experience may help patients in their attempts to intend the world in a new and meaningful way.

\section{Rhythm and meditation on beauty}

In the context of cultural phenomenology, perception and intentionality are not seen as simply subjective practices. According to Merleau-Ponty, the perceiver, the thing perceived, and the act of perceiving all seem to come together in a manner that makes clear distinctions difficult:

As I contemplate the blue of the sky I am not set over against it as an acosmic subject; I do not possess it in thought, or spread out towards it some idea of blue such as might reveal the secret of it, I abandon myself to it and plunge into this mystery, it 'thinks itself within me, I am the sky itself as it is drawn together and unified, and as it begins to exist for itself; my consciousness is saturated with this limitless blue. (Merleau-Ponty 2005: 249, italics in original)

This famous quote from Merleau-Ponty aptly reflects what Helena told me about her relationship to 'aesthetics'. Helena was around 45 years old, and she was dying from breast cancer. She had been diagnosed three years before, but over the past year her condition had gotten significantly worse. As I knew Helena's background and hobbies - she had studied various arts and humanities in the university and was very interested in literature, as well as the visual arts I had talked to her explicitly about aesthetics and art.

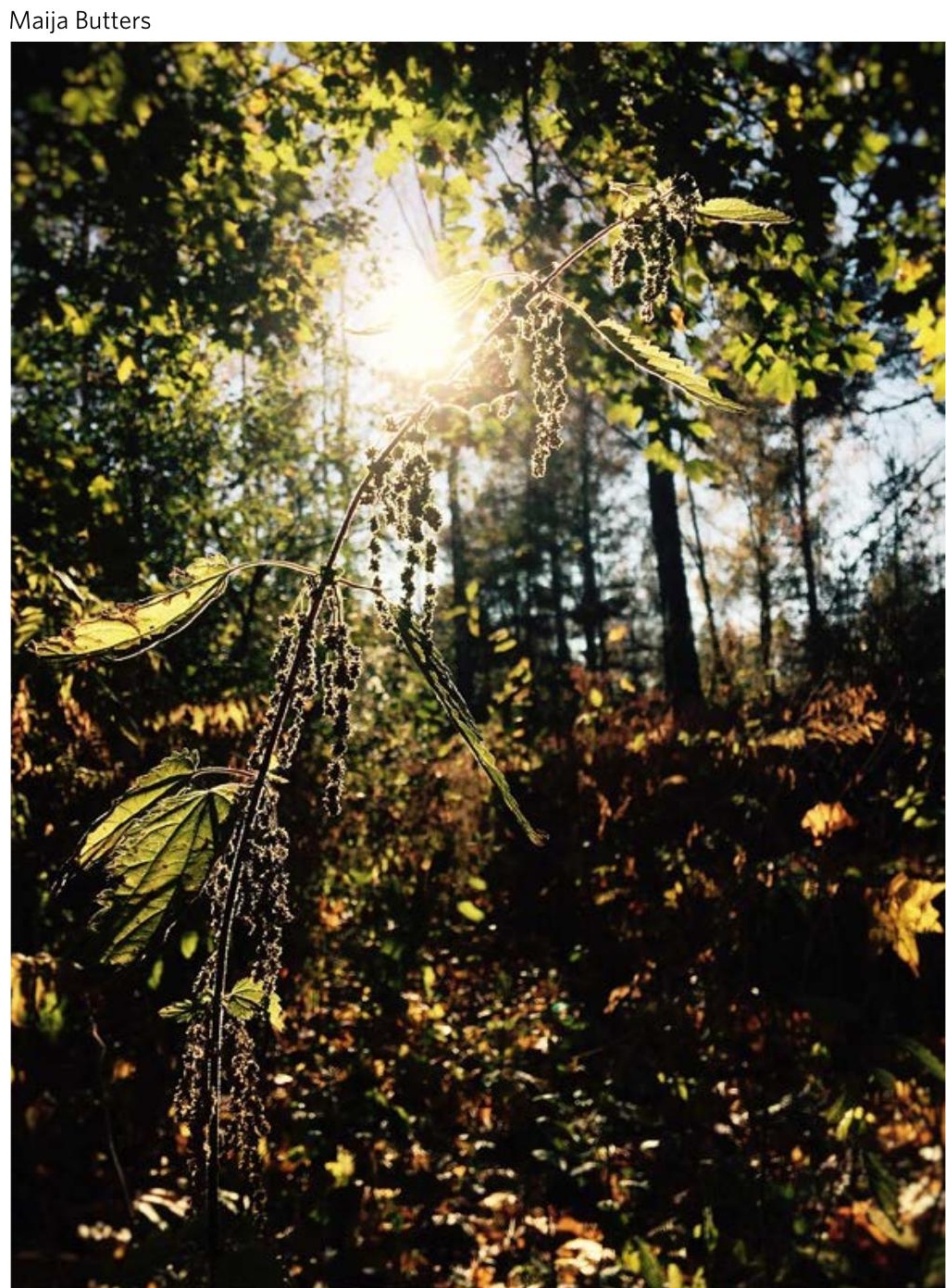

Autumn light in the forest.

When I asked what aesthetics meant to her, she told me the following:

$\mathrm{H}$ : Aesthetics has always been important to me, like in everyday life at home and so forth... It is one of those [things] that really helps me in life, that if there is something beautiful around me. When I became sick I was in the beginning still able of to go out a lot [into nature], I have always liked walking a lot, just to the nature like... from the nature you get anyhow so much power, but seeing the beauty there... It helps me a lot that... How would I put this? Maybe it is somehow meditative to me. It has always been important to me that wherever I am, I always try to look for the most beautiful spot of the place, and then just plunge (sukellan) into it, or vanish... stare at it or... like... 
Me: Like you draw (ammennat) from it?

$\mathrm{H}$ : Yes, I draw from it. I noticed with this sickness that... Like I have always had this, but I noticed that since becoming sick, it has become much stronger. I am terribly glad that I have this kind of... Could I call it a skill? An ability to do that. Because it has helped me terribly a lot, especially when I have been really sick, just lying in bed, that then something so small, some small detail can help, like just having a candle on the table to just stare at... well, a candle is perhaps a very typical focus of meditation anyhow, but just having something on which you can focus your gaze, something visual...

Helena then continued to tell me about her previous apartment, which had had huge windows opening onto a forest. She had the curtains taken away so that she could have an unobstructed view. During the worst moments of physical sickness, Helena said that she had simply stared outside for hours: 'there was always something to see, in the clouds or trees... It has really been... the salvation of salvations to me, this skill.' I asked Helena if this sort of 'plunging into visual details' could happen with manmade art objects? Helena exclaimed:

$\mathrm{H}$ : Oh yes! That is why it has been so wonderful to me that my daughter is now doing photography. It brings me such great enjoyment in life. ... What I share in Facebook, combining a photo with some text... although on Facebook they just look like an image and a text, for me they are powerful... like I get a really deep source of power from them. I really experience them like a kind of bigger creation... that there is a picture and that I am able to create some text to go with it. That is actually one of my dreams, like we talked about the things one would want to do before... that I would do a book with my daughter, where there are her photos and my text.

This wish was important to Helena. She told me that sometimes she was unable to sleep at night because she was anxiously thinking about the book and fearing to not have enough time to finish it. Then she continued about aesthetic objects:
$\mathrm{H}$ : I also have certain important objects, like we all do, whose mere presence in a given space empowers me. I have two books that work like this for me: a poetry book and one that combines images and text. They are wonderful as texts, but also as aesthetic objects they are insanely great.

When I tried to ask her what exactly happened during those aesthetic moments when she was 'plunging in', she answered:

$\mathrm{H}$ : For the most part it is just like... well, I experience it like 'being present in the moment', which is today such a cliché expression [laughs], but in those moments... It is an experience of non-stressedness. It can be liberating. ... But at its best, it feels like it opens up another dimension of reality, especially at those times when there has been some difficult situation of hardcore pain or intense psychic pain. It has been really great then that there are those kinds of gateways... that one can get away.

Having reflected on this, Helena shared that she was probably inclined to sense aesthetics in this way because of her heavily religious background and childhood. She came from a very religious community which not only had a strong Christian ethos, but also 'a vivid charismatic surrounding where all kinds of things, even strange ones, were happening. As an adult, Helena no longer agreed with the Pentecostal theology of her childhood church, yet she felt that her background had taught her that the world was not merely composed of visible, materialistic dimensions: 'That is what I am thankful for, that gift that I have gotten, since I was small, that there exist also other worlds where you can... like, it isn't just about this reality where we are, but there also exists some other, very rich reality...'

When Helena speaks about 'plunging into' the object, she literally repeats Merleau-Ponty's description of the act of perceiving. Staring at the object, she

9 The connection that Helena herself draws between her present aesthetic imagination and her Pentecostal background is a very interesting one, which demands to be elaborated more, especially on the basis of Tanya Luhrmann's 'absorption hypothesis' (Luhrmann et al. 2010). 
was able to almost 'vanish' into it. Here again is the familiar blending of the inner and the outer, already seen with Martti's story. Helena's experience also has a mystical, even magical, flavour to it. Yet, the common denominator in all of the different instances she was describing - whether her experience had to do with nature, visualizations of details, or material, artistic objects - was aesthetics. It was aesthetics that ultimately seemed to empower her.

Another interesting element found in Helena's experience is rhythm. Helena talked about times of being severely sick and in pain, unable to do anything but lie in bed. Time easily loses structure when 'nothing happens'; this was a general remark by many patients. Structure and rhythm are necessary in order to orient in the world. Dewey writes extensively about rhythm, not only in aesthetic experiences but also as an aspect of nature. For Dewey, rhythm is one of the main qualities of the material world, which makes existence of artistic forms possible. According to Dewey (1980: 150), rhythm is 'a universal scheme of existence' and, as such, it also 'pervades all the arts': 'Underneath the rhythm of every art and of every work of art there lies, as a substratum in the depths of the subconsciousness, the basic pattern of the relations of the live creature to his environment.' I suggest that by dwelling in beauty and meditating on various aesthetic aspects of the natural world, Helena was able to find traces of these rhythms of life, which not only provide aesthetic experiences but reflect existence itself in a very biological sense.

Helena's comment about an aesthetic experience being a 'gateway' to another dimension of reality approaches Susanne Langer's (1959) notion of the virtuality of art. Art as a virtual space or a virtual time means that art creates virtual or imagined dimensions for us to enjoy - or that ultimately art is those dimensions. This reminds of what Dewey wrote about imagination. When studying the psychology of an aesthetic experience, Dewey accords imagination a special place in the processes of artistic creativity. But imagination is not only at play during moments of making or observing art. Dewey (1980: 267) writes about the general ways in which the mind meets the world: 'When old and familiar things are made new in experience, there is imagination. When the new is created, the far and strange become the most natural inevitable things in the world. There is always some measure of adventure in the meeting of mind and universe, and this adventure is, in its measure, imagination.' This, in turn, echoes Hepburn's concept of 'metaphysical imagination' mentioned above.

Aesthetic experiences, as they present themselves here, are moments where the familiar meets the unknown, the strange and even the scary. Aesthetic experiences are flavoured and saturated by imagination, thereby creating a space where a person is able to re-orient and find new, relevant metaphysical meanings. Furthermore, there is an embodied quality in the process, as Andrew Irving (2009: 298) states in regard to visual art: '...the dialogue between image and imagination is in part a physical, bodily phenomenon that involves movement and being moved through exchanges of meaning. I would suggest that the reason why aesthetic experiences were so immensely 'helpful' and served as a 'salvation' to Helena is that these moments enabled her to establish and maintain a relationship or connection with the world. This connection, which the Christian philosopher Gabriel Marcel (1973) would probably call 'ontological exigence', renders existential orientation and metaphysical meaning-making possible.

In Helena's case, aesthetics supported her survival during extremely challenging existential moments. Furthermore, aesthetic experiences were essential for her metaphysical understanding of the world, and they also assured her about the existence of 'another dimension', which in turn gave death a special position. The manner in which Helena experienced her environment, as well as her intense wish to complete the book project, brings me to existentialist views on aesthetic experience.

\section{Art as revelation: the meaning of aesthetic experience}

Being a naturalist, Dewey took aesthetic qualities, such as rhythm, to fundamentally be properties of nature itself. For existentialists such as Jean-Paul Sartre, however, meanings are constituted by our acts and by our consciousness intending the world in a certain way and imposing certain order on external phenomena. In and of itself, the world does have meanings, but ultimately it requires human consciousness to reveal them: 'With each of our acts, the world reveals to us a new face. But, if we know that we are directors of being, we also know that we are not its producers' (Sartre 1949: 38-39).

At the core there lies a tension: our perception 'reveals' the world, making us 'directors of being', yet 
simultaneously we know that the world will continue even after we are no longer perceiving it. According to Sartre, it is precisely this paradox and a feeling of being inessential to the world that gives people the urge to create art:

One of the chief motives of artistic creation is certainly the need of feeling that we are essential in relationship to the world. If I fix on canvas or in writing a certain aspect of the fields or the sea or a look on someone's face which I have disclosed, I am conscious of having produced them by condensing relationships, by introducing order where there was none, by imposing the unity of mind on the diversity of things. That is, I feel essential in relation to my creation. (Sartre 1949: 39, my italics)

The audience needs to be able to recognize these structures in order to enjoy art aesthetically. But what happens in situations where a person suddenly experiences their environment, or a detail in it, in a deeply aesthetic manner? I would claim that an act of perceiving can in itself become the sort of creative act which Sartre describes above. This is actually what happened to Helena: she was able to perceive beauty and aesthetic experiences in many places, as long as she concentrated. Just as in Sartre's quote above, she condensed relationships, introduced order, and imposed unity on her environment in order to gain an aesthetic experience. From an existentialist's point of view, she was practising her human freedom. This act, which reveals her attitude towards the world, was her existential choice (Deranty 2015).

We can also find this type of artistic creativity in my final story. Oiva was a 70-year-old artist who had been fighting cancer for several years. During the six months I knew him, his condition had gotten steadily worse. Previously he had received home care, but finally he was admitted to the hospice ward. He knew he only had a matter of days left, and we were having long conversations. Even when severely ill and so close to death, he was enthusiastic about telling his thoughts to me. He shared a memory about his wife's death, which had happened already some years before. Because she had been cremated, he had gone with his son to pick up the urn to take it for burial in the cemetery.

He explained: 'I remember the picture from that situation. There was only me, my wife's urn, my son and the cemetery worker who showed us the place.... The picture that stayed here [pointing to his head]... it was...' Oiva was getting emotional, and it became difficult for him to utter the words. "When... my son was born...' Oiva started crying now. I had never seen him so moved. 'My wife was carrying him like this in her arms, bringing him home. Now, then, the son was carrying his mother in his arms... It was a very touching scene (näky) and metaphor (vertauskuva), so later at home I drew a picture of it...' Oiva added that he had never shared that personal picture with his son. He couldn't, he confessed.

This touching memory, which involved the most beloved persons in Oiva's life, had taken the form of a mental picture, a snapshot in his mind, which he then worked with to create an art piece. The moment captured birth and death, the human cycle of life. Even though it depicted reality in a rather painful way, it was a beautiful picture, and there was nothing wrong with it. One can see a parallel between Sartre's understanding of artistic creation and what happened with Oiva. His perception was artistic, even before he created a concrete art piece about it. It was how his mind met with reality. From a Deweyan point of view, Oiva simply witnessed the fundamental characteristics of nature with its ever-continuing cycle of birth and death, whereas from a Sartrean point of view, his consciousness intended reality in such a way that it constituted a metaphysical understanding of the cycle of life. Whether we look at the story from Deweyan or Sartrean perspectives, Hepburn's statement about 'aesthetics revealing something fundamental about how things really are' is again apt here.

\section{Aesthetics as metaphysical meaning-making}

Returning to my initial question regarding the story of Heidi and a blackbird - how did she suddenly understand her situation and approach death, and how did the incident become so meaningful to her that she needed to share it with me? - I believe that the aesthetics of the scenery helped Heidi to renew her relationship with the world and that it thereby reinforced her intentionality towards life and death. Aesthetic experience, which was constituted by perceiving structure and rhythm in nature and also by feeling an embodied connectedness to nature, reinforced Heidi's apprehension about the cyclical nature of existence, that is, the continuous cycle of birth and death. Following Langer's line of thought, art can 


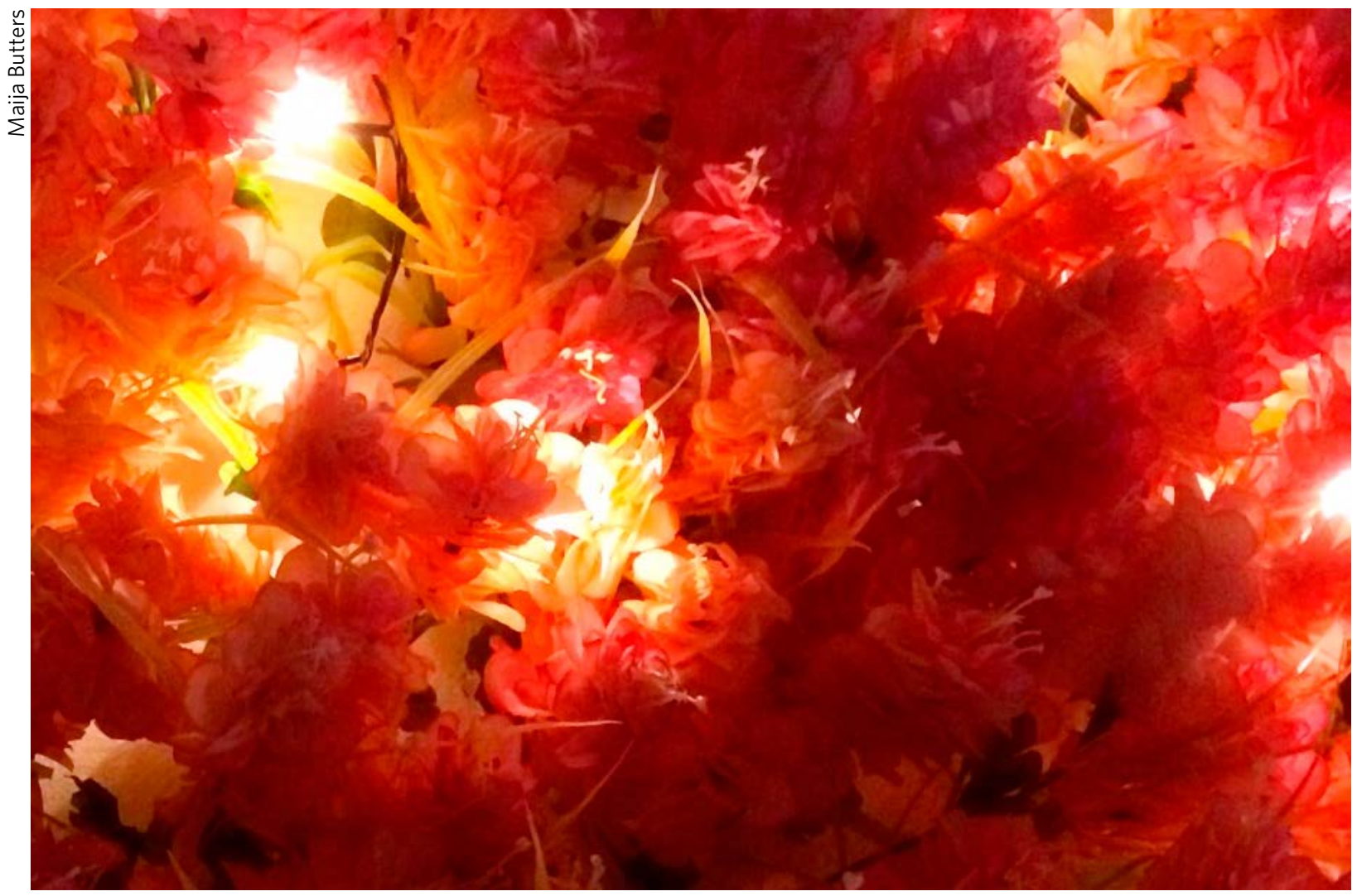

Detail from an installation 'Picnic for the sad' by Heidi Elisabeth Hänninen (Huuto Galleria, 2016).

be seen as 'a non-discursive sign system to express and organize inner thoughts' (William and Boyd 2006: 287). Aesthetic experience creates patterns and rhythm for an otherwise chaotic situation, which can be hard to think of and speak about with propositional language. Seeing the world in this way enabled Heidi to discover a personal place in the larger context of life; she was able to make sense of her coming death. The experience thus became metaphysical in its flavour: through the experience she was able to form and also express her understanding about the ultimate nature of being.

As Dewey and Hepburn point out, imagination can play a significant role here. It is because of the imaginative flavour of an aesthetic experience that such meaning-makings are possible. Aesthetics offers a possibility to assert a certain metaphysical perspective towards life and death; it can serve as a reinforcement of one's metaphysical views. Imagination in the context of aesthetic experiences can also be seen as virtuality, a concept that was especially important in Langer's art theory. Aesthetics as virtual space and virtual time resembles some aspects of ritual. In both art and ritual, aesthetics creates a virtual space for absorbing, tolerating, and even celebrating tensions and paradoxes of life. In this kind of virtual space, things otherwise impossible become possible. Similarly, in a ritual frame we enter a virtual 'as if' world of possibilities (see Utriainen 2016).

We have looked in detail at how aesthetic meaning-making happens, yet we have not discussed possible sociocultural reasons why aesthetics seems to offer a preferred way of handling these metaphysical issues. According to existentialism, perception of the world includes a priori values held by the perceiver. This is to say that the way in which consciousness intends the world is intrinsically dependent on the values of the person, and therefore the content of perception is ultimately determined by the perceiver's value system. Marcel has even claimed that the basic ontological experience of existence in general, the experience that something exists, is dependent on one's desire for it; without desire, there is no experience (Deranty 2015). One could claim, therefore, that the phenomenon of actually having an aesthetic experience - rather than a religious one, for instance - is due to the subject's prior values and perspectives.

The philosopher Aarne Kinnunen comes to a 
similar conclusion in his important book on aesthetic experience, Esteettisestä elämyksestä (1969). ${ }^{10} \mathrm{After}$ using several theoretical approaches to analyse the concept of aesthetic experience, Kinnunen resolves that although an all-encompassing definition is impossible, aesthetic experiences surely exist, and they can even be life-changing in their importance. The factors that determine whether a given experience is aesthetic - and not religious or cognitive, for instance - have to do with the experiencer's worldview. Regarding the foundation of an aesthetic experience, Kinnunen (1990: 104) writes: '...there may be a conception of art, moral ideology, or religion, or even epistemology. Without them it cannot exist.' ${ }^{\prime 1}$ Depending on one's ideological worldview, aesthetic experiences can get different explanations.

Kinnunen (1990: 105) adds that aesthetic experience belongs to the same category as mystic, religious, and peak experiences. ${ }^{12}$ In order to have a religious experience, though, one must have religious vocabulary and a worldview that renders it possible. This approach is akin to Ann Taves's attributional theory which suggests that whether experiences are labelled 'religious' or 'spiritual' is dependent on the pre-existing beliefs and practices as well as the web of concepts related to them (Taves 2009: 163). In terms of the metaphysically meaningful moments my research participants shared with me, they did not include religious vocabulary, attributes, or definitions in their stories (with the exception of Martti). Instead, their special moments were not only told with aesthetic vocabulary, but they were essentially about aesthetics. Even Martti, who gave his experience a religious interpretation, emphasized that it was the embodied auditory and visual aspect of the experience that was so impressive and perplexing to him. ${ }^{13}$

10 I would like to thank Oiva Kuisma for recommending Kinnunen's book to me.

11 '[Esteettisen elämyksen perustana] voi olla taidekäsitys, moraalinen ideologia tai uskonto, vieläpä jokin tiedonkäsitys.' My translation.

12 Kinnunen uses the term todellisuuskäsitys. Literally this means 'understanding of reality', but I freely translate it here as 'peak experience'. Another possible translation could be the Buddhist term satori, which expresses a sudden realization of the nature of reality.

13 My aim has not been to evaluate the religiosity of my research participants, but I have categorized my research participants emically. Of the four persons mentioned here, one adhered to a Christian world

\section{Conclusion}

My research suggests that some contemporary Finns relate to the existential crisis of dying via aesthetics rather than religion. My research data includes a number of additional examples which were not possible to include here, but nonetheless pose other interesting aspects about the meaning of aesthetics to hospice patients (e.g. their process of making art, blog writing). Here I have focused especially on the actual experiencing of aesthetics, analysing it through the theories and ideas of Dewey, Merleau-Ponty, and Sartre. While I have examined how meaning-making happens in this context, important questions about the specific content of the patients' metaphysical thought remain a matter of further study.

The theme of aesthetics emerged in a number of ways among the terminal patients. For some, aesthetics provided a relief and a break from pain, whether physical or mental, by opening a window to somewhere else, occasionally even to another dimension of being. For others, aesthetics brought about a sudden realization regarding their existential situation. Aesthetic experiences meant different things to each of the patients, but for all of them aesthetics and metaphysics came together one way or another. Aesthetics provided a way of approaching and thinking about death, as well as a language to communicate about it. Perhaps even more importantly, it was with the help of aesthetics that patients found a new type of meaningful relationship with the world.

In regards to the kinds of meanings my research participants found in these moments, for various reasons I have chosen the adjective 'metaphysical'. Metaphysics is ultimately about negotiations over many aspects of quotidian life and matters of ultimate reality, including things that can be - but do not need to be - seen as religious or spiritual. Aesthetic experiences can reveal fundamental aspects of 'how things really are. To some, these may at times point to something completely other, be it immanent and mundane or a transcendent other, as Hepburn (2004: 127) suggests. Opposed to religious traditions, aesthetics remains open for various interpretations in regards to metaphysical claims about 'how things really are'.

view, but the other three had more ambiguous relationships with things 'deemed religious' (Taves 2009), ranging from believing in God but not following any Christian theology to having a very distant relationship with God. 
Yet aesthetics seems to enable and empower without propositional or theological limitations. Therefore, I would argue that aesthetics supports metaphysical meaning-making.

These findings about the meaningfulness of art and aesthetics to people in extreme existential crises naturally raise some questions about practical care for the dying. While art and aesthetics are known to be beneficial for well-being, by elaborating on the richness and diverse implications of aesthetic experiences on an existential level, my study hopes to provoke a deeper understanding of the transformative potentiality of aesthetics in palliative care.

\section{Acknowledgements}

The author wishes to thank the Doctoral School of History and Cultural Heritage at University of Helsinki and the Finnish Cultural Foundation for funding the study.

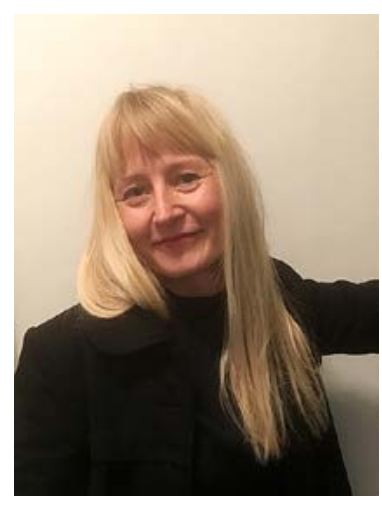

Maija Butters is a cultural anthropologist and doctoral candidate in the Science of Religions at Helsinki University. Previously she has written on Tibetan Buddhist art. Her dissertation study 'Personal landscapes of death in Finland' focuses on the experiences of hospice patients. She is especially interested in the imageries of modern death and dying.

\section{References}

Csordas, Thomas J., 1990. 'Embodiment as a paradigm for anthropology', Ethos: Journal of the Society for Psychological Anthropology, 18(1), pp. 5-47, doi 10.1525/eth.1990.18.1.02a00010

-1994. 'Introduction: the body as representation and being-in-the-world' in Embodiment and Experience: The Existential ground of culture and self, ed. Thomas J. Csordas (Cambridge University Press)

-1999. 'Embodiment and cultural phenomenology' in Perspectives on Embodiment: The Intersections of Nature and Culture, eds Gail Weiss and Honi Fern Haber (New York, Routledge), pp. 143-62

Deranty, Jean-Philippe, 2015. 'Existentialist aesthetics' in The Stanford Encyclopedia of Philosophy, ed. Edward N. Zalta, <http://plato.stanford.edu/archives/spr2015/ entries/aesthetics-existentialist/> (accessed 6.6.2016)

Desjarlais, Robert, 2016. Subject to Death: Life and Loss in a Buddhist World (University of Chicago Press)

Dewey, John 1980 (1934). Art as Experience (New York, A Perigee Book)
Eck, Diana L. 1981. Darśan: Seeing the Divine Image in India (Chambersburg, Anima Books)

Heinämaa, Sara, 2010. 'The sexed self and the mortal body' in Birth, Death, and Femininity: Philosophies of Embodiment, ed. Robin May Schott (Bloomington, Indiana University Press), pp. 73-98

Hepburn, Ronald, 2004. 'Landscape and the metaphysical imagination' in The Aesthetics of Natural Environments, eds A. Carlson and A. Berleant (Peterborough, Broadview Press), pp. 127-40

Howes, David, (ed.) 1991. The Varieties of Sensory Experience: A Sourcebook in the Anthropology of the Senses (University of Toronto Press)

-2015. 'The extended sensorium: introduction to the sensory and social thought of Francois Laplantine' in The Life of the Senses: Introduction to a Modal Anthropology by Francois Laplantine (London, Bloomsbury Academic), pp. vii-xiv

Howes, David, and Constance Classen, 2014. Ways of Sensing: Understanding the Senses in Society (London, Routledge)

Ingold, Tim 200o. The Perception of the Environment: Essays in Livelihood, Dwelling and Skill (London, Routledge)

-2011. Being Alive: Essays on Movement, Knowledge, and Description (London, Routledge)

Irving, Andrew, 2009. 'The color of pain', Public Culture, 21(2), pp. 293 -319, doi: 10.1215/08992363-2008-030

-2013. 'Into the gloaming: a montage of the senses' in Transcultural Montage, eds C. Suhr and R. Willerslev (Oxford and New York, Berghahn), pp. 76-95

-2016. The Art of Life and Death: Radical Aesthetics and Ethnographic Practice (University of Chicago Press)

Jackson, Michael (ed.), 1996. Things As They Are: New Directions in Phenomenological Anthropology (Bloomington, Indiana University Press)

-2013. Lifeworlds: Essays in Existential Anthropology (University of Chicago Press)

Johnson, Mark, 1987. The Body in the Mind: The Bodily Basis of Meaning, Imagination, and Reason (University of Chicago Press)

-2007. The Meaning of the Body: Aesthetics of Human Understanding (University of Chicago Press)

Kinnunen, Aarne, 1990 (1969). Esteettisestä elämyksestä (Helsinki, Yliopistopaino)

Lakoff, George, and Mark Johnson, 1999. Philosophy in the Flesh: The Embodied Mind and Its Challenge to Western Thought (New York, Basic Books)

Langer, Susanna K., 1959 (1953). Feeling and Form (London, Routledge \& Kegan Paul Limited)

Laplantine, Francois, 2015. The Life of the Senses: Introduction to a Modal Anthropology, tr. Jamie Furniss, orig. 2005 in French (London, Bloomsbury Academic)

Luhrmann T. M., Howard Nusbaum, and Ronald Thisted, 2010. 'The absorption hypothesis: learning to hear God in Evangelical Christianity', American Anthropologist, 112(1), pp. 66-78, doi:10.1111/j.1548-1433.2009.01197.x 
Marcel, Gabriel, 1973. Tragic Wisdom and Beyond (Evanston, Northwestern University Press)

Merleau-Ponty, Maurice, 2005 (1945). Phenomenology of Perception (Taylor and Francis e-Library)

Meyer, Birgit, 2015. Sensational Movies: Video, Vision and Christianity in Ghana (Berkeley, University of California Press)

Mitchell, Jon P., and Michael Bull (eds), 2015. Ritual, Performance and the Senses (London, Bloomsbury Academy)

Morgan, David, 2005. The Sacred Gaze: Religious Visual Culture. The Matter of Belief (Berkeley, University of California Press)

-(ed.) 2010. Religion and Material Culture in Theory and Practice (New York, Routledge)

Nummelin, Sanna, 2011. 'Kulttuurin hyvinvointivaikutukset: onnea, elämyksiä, terveyttä, Tutkimuskatsauksia 1/2011 (Turun kaupunki, Kaupunkitutkimus- ja tietoyksikkö), <https://www.turku. fi/sites/default/files/atoms/files/tutkimuskatsauksia_2011-1.pdf>

Pink, Sarah, 2009. Doing Sensory Ethnography (London, Sage Publications)

Plate, Brent S., 2005. Walter Benjamin, Religion and Aesthetics: Rethinking Religion Through the Arts (New York, Routledge)

Puolakka, Kalle, 2014. 'Dewey and everyday aesthetics: a new look', Contemporary Aesthetics, 12, <http://www. contempaesthetics.org/newvolume/pages/article. php?articleID $=699>($ accessed 23.5.2016)

Sartre, Jean-Paul, 1949. What is Literature? Tr. Bernard Frechtman (New York, Philosophical Library)

Shusterman, Richard, 1999. 'Somaesthetics: a disciplinary proposal', The Journal of Aesthetics and Art Criticism, 57(3), pp. 299-313

-2012. Thinking through the Body: Essays in Somaesthetics (Cambridge University Press)

Taves, Ann, 2009. Religious Experience Reconsidered: A Building Block Approach to the Study of Religion and Other Special Things (Princeton University Press)

Thorgeirsdottir, Siridur, 2010. 'Conversations with ourselves in metaphysical experiences of nature' in Conversations with Landscapes, eds Karl Benediktsson and Katrín Anna Lund (Farnham, Ashgate), pp. 13-26

Utriainen, Terhi, 2016. 'Ritually framing enchantment: momentary religion and everyday realities', Anthropology of Finland (forthcoming, to be published 2016)

Williams, Ron G., and James W. Boyd, 2006. 'Aesthetics' in Theorizing Rituals, vol. 2: Annotated Bibliography of Ritual Theory, 1966-2005, Numen Book Series, eds Jens Kreinath, J.A.M. Snoek and Michael Stausberg (Leiden, Brill), pp. 285-305 